\title{
Fetal Engagement
}

National Cancer Institute

\section{Source}

National Cancer Institute. Fetal Engagement. NCI Thesaurus. Code C92784.

A position adopted by the fetus during labor when its head moves down into the

maternal pelvic cavity. 